\title{
Indissociabilidade entre ensino e pesquisa: a qualidade da graduação em tempos de democratização
}

\section{Maria Isabel da Cunha*}

\section{Resumo}

$\mathrm{O}$ texto discute a premissa da indissociabilidade do ensino e da pesquisa no contexto da pedagogia universitária. Procura compreender as formas de produção desse discurso e as recontextualizações necessárias para inserir-se na atualidade. Afirma que a nebulosidade conceitual que envolve a relação ensino e pesquisa tem consequências nos processos de ensinar e aprender na universidade e no projeto de formação dos docentes que atuam nesse nível de ensino. Recupera a perspectiva epistemológica do ensino com pesquisa, enfatizando a necessidade de fazer rupturas com a concepção da ciência moderna que incide fortemente nas práticas cotidianas de ensinar e aprender. Analisa as exigências que esse movimento traz para a didática da educação superior, na direção de inovaçóes pedagógicas que tomem a relação ensino e pesquisa como um princípio metodológico.

Palavras-chave: Qualidade. Relação ensino e pesquisa. Pedagogia Universitária.

* Doutora em Educação pela Universidade Estadual de Campinas. Professora da Unisinos. 
A problemática da pedagogia universitária apresenta-se com força nos espaços institucionais da educação superior, dadas as mudanças no plano social e cultural que repercutem na constituição atual da universidade.

No contexto das práticas pedagógicas os desafios têm sido intensos. Entre eles, um dos mais exigentes está o de pensar a dimensão superior que caracteriza os estudos do terceiro grau e a condição universitária desses estudos. Para alguns estudiosos essa condição se estabelece pela relação ensino e pesquisa que caracteriza esse nível de educação. Para outros, a denominação de superior significa uma condição de elitização, explicitando que o acesso a esse grau de ensino deve pautar-se pela meritocracia e seletividade. Há, ainda, os que crêem que o adjetivo superior está ligado ao mundo das profissóes e que algumas delas exigem uma preparação mais intensa na sua base teórica.

Certamente há sustentação para cada um desses argumentos. Talvez os três possam estar articulados mesmo que no campo ideológico possa haver dispersão de significados entre eles. O fato é que a condição da educação superior, por longo tempo, foi privilégio das camadas sociais mais favorecidas, reforçando a relação entre acesso educacional e classes sociais. Mesmo considerando os espaços universitários públicos, o acesso e permanência dos mais pobres sempre foi exceção, muitas vezes usada para mascarar a suposta igualdade de oportunidades. Essa realidade se apresenta como um impasse para as sociedades que se explicitam como democráticas. Parece haver poucas dúvidas sobre as exigências acadêmicas qualificadoras da formação, mas, ao mesmo tempo, há uma forte compreensão de que é preciso progredir nos processos de inclusão democrática aos bancos universitários.

Refletir sobre a educação superior, sua qualidade e relação com o discurso da indissociabilidade do ensino, pesquisa e extensão é o objetivo desse texto. Longe de considerar que este tema seja simples e objetivo, a intenção é problematizar, com base na literatura contemporânea e na empiria investigativa, uma questão à qual atribuímos fundamental importância, especialmente pelos seus desdobramentos no campo da pedagogia universitária.

As mudanças no mundo do trabalho têm afirmado com intensidade progressiva a sua relação com os níveis de escolarização. A escolarização, considerada como um bem individual, ligada ao conceito de cidadania, passou a ser vista como uma questão de Estado, definindo as relaçóes econômicas competitiva entre as naçóes. Mede-se o PIB e o desenvolvimento 
dos diversos países pelo grau de escolarização da sua população e pelo patamar de conhecimentos que ela detém. As avaliaçóes externas de larga escala promovidas por organismos internacionais classificam os escores reveladores dos índices de desenvolvimento que, por sua vez, terão repercussôes nos investimentos econômicos dos organismos mundiais.

Essa condição tem estimulado os países emergentes a ampliarem o acesso à educação superior. A progressiva ampliação da escolarização fundamental também vem exercendo pressão social para um número maior de postos na universidade. No caso do Brasil, essa demanda crescente encontrou estímulo nas políticas neoliberais dos anos noventa, favorecendo uma forte expansão privatista da educação superior, facilitada por legislaçóes que flexibilizaram as exigências para esse nível de ensino.

Embora com fortes críticas a essa política, há de se reconhecer que a mesma provocou uma mudança no quadro de matrículas, mesmo que os números ainda se distanciem do patamar desejado, quando comparados aos de outros países com o mesmo índice de desenvolvimento. Na mesma direção, os anos 2000 alavancaram a expansão pelo setor público, há muito tempo estagnado. Foram expandidas as vagas nas universidades federais e criadas outras tantas, especialmente assumindo critérios de interiorização e democratização do acesso, visando à inclusão social e o desenvolvimento de regiôes do país até então pouco atendidas. Ao mesmo tempo, houve expressiva expansão da rede de educação tecnológica, que progressivamente vem assumindo a missão e as características típicas da educaçáo superior.

Esse processo vem atendendo ao princípio da democratização que passa pelas condições de ampliação do acesso e permanência de um maior contingente de jovens na educação superior, incluindo as chamadas políticas de cotas. Entretanto, as alternativas de democratização são mais exigentes "porque questionam a universidade em seu todo, não só em relação a quem a frequenta, mas também ao como os conhecimentos são transmitidos a quem a frequenta" (SANTOS, 2010, p. 73). Diferencia-se, então, a massificação da democratização, e essa condição é fundamental para garantir uma formação de qualidade.

Mencionar o termo qualidade tornou-se senso comum nos discursos educacionais, porém, também é reconhecida a compreensão da polissemia desse termo. Ele não é autoreferenciado, precisa ser adjetivado, revelando os parâmetros e valores que estão em jogo na sua configuração. 
Nos aportes de Cortella, encontramos uma visão de qualidade que se distancia das proposiçóes alicerçadas na perspectiva de produtividade. $\mathrm{O}$ autor traz a expressão qualidade social para explicitar um parâmetro comprometido com a condição humana e cidadã. No caso da educação, "significaria uma sólida base científica, formação crítica de cidadania e solidariedade de classe social” (1998, p. 14-15). Facilmente se percebe nessa proposição um posicionamento valorativo que se distancia da neutralidade generalizadora, mas que assume uma condição atrelada a um referente axiológico, portanto político.

Santos (2000), na procedente crítica que faz do paradigma dominante que presidiu a ciência moderna, refere-se especialmente ao intento de atribuir neutralidade ao conhecimento científico, dicotomizando meios e fins. Advoga, através da sua proposição do paradigma emergente, em favor de uma ciência comprometida, "um conhecimento prudente para uma vida decente" (SANTOS, 2000, p. 242). Essas compreensōes encaminham a critérios de qualidade que visivelmente assumem a territorialidade de sua produção e as opçôes políticas dos atores. Servem para mostrar a complexidade de tratar o conceito de qualidade e seus desdobramentos em termos exclusivos de indicadores quantitativos. Especialmente chamam a atençấo para o fato de que a expressão qualidade necessita de um conteúdo discursivo que se afaste das generalizaçóes universais vindas do senso comum. Atribuir qualidade requer a tomada de posiçóes frente aos fenômenos políticos e sociais.

Se a expansão é condição fundamental para diminuir a desigualdade social e progredir rumo a uma sociedade com maior equidade, o desafio que se apresenta refere-se a como dar a esse processo a garantia da necessária qualidade da educação superior no país. É certo que isso não se faz com um passe de mágica. Nenhuma das atuais Universidades com alto prestígio começou suas atividades nesse patamar. Foram muitos os investimentos humanos e materiais que favoreceram o estágio atual de consolidação. É preciso certo grau de paciência histórica e um alto grau de investimento para consolidar uma universidade. Mas, acima de tudo, é preciso acreditar nas suas possibilidades e potencializar energias para a sua construçáo. Essa extrapola os necessários prédios e laboratórios. Exige compromisso humano, sensibilidade social e investimento acadêmico. Precisa, principalmente, reflexão sobre o Projeto Político Pedagógico que orienta a gestão e a ação 
acadêmica, discutindo o significado de qualidade e seu desdobramento nas práticas acadêmicas.

Historicamente temos tomado, no Brasil, a compreensão de que a relação de indissociabilidade do ensino, pesquisa e extensão é que caracteriza a qualidade da educação superior e que a compreensão de conhecimento sustenta essa relação, sempre a entendendo num contexto cultural. Estudos como os de Mazzili (2007), Enriconi (2008), Severino (2009a) e Machado (2009) são exemplos de contribuiçôes recentes sobre esse tema, bem como as clássicos contribuições de Paoli e Balzan (1985), Demo (1993), Stenhouse (1998), Zabalza (2002) e Barnett (2008) são recorrentes quando se toma esse objeto de reflexão e pesquisa.

O empenho em fazer valer essa premissa mobilizou a sociedade civil e a base sindical e associativa da educação superior na ocasião da definição da Constituição Brasileira, em 1988. Esse pressuposto encontra guarida no imaginário social da comunidade acadêmica e em muitos setores da sociedade civil. Parece uma condição tácita e universalmente aceita que a indissociabilidade do ensino e da pesquisa é um valor no contexto da educação superior. Entretanto, talvez por ser tão universal essa aceitação, a falta de questionamento tem dificultado, também, estudos e reflexóes mais rigorosos sobre a pertinência e natureza dessa relação.

Ramsden e Moses (1992, p. 273) argumentam que:

[...] há poucas crenças no mundo acadêmico que suscitam defesas táo apaixonadas como a opiniấo de que a docência e a investigação são atividades complementares e que mutuamente se beneficiam. Mas há poucos estudos empíricos realizados acerca desse vínculo.

A posição do autor revela que esse não é um fenômeno local, mas que mobiliza reflexóes no mundo inteiro, especialmente em momentos de históricas mudanças no perfil da educação superior, em especial no ensino de graduação.

Para Severino (2009b), ${ }^{1}$ é desde a modernidade que a perspectiva de conhecimento veiculada na universidade assume uma ruptura com as tradicionais formas de perceber o conhecimento como "transmissão da verdade, coligada e sistematizada nos sistemas conceituais da metafísica e 
da teologia”. Entretanto, ainda estamos longe de assumir uma posição mais consistente e sedimentada a respeito de tal relação.

Não surpreende identificar que essa perspectiva conceitual é muito pouco tensionada nos espaços acadêmicos. No Brasil, ela fez parte da concepçáo universitária que se instalou na segunda metade do século XX, por conta de diferentes legislaçóes. Certamente a chamada Reforma Universitária instituída pela Lei no 5540 de 1968 (BRASIL, 1968) foi precursora desse movimento. Instituindo a departamentalização, silenciou a organização em torno das carreiras e cursos - inclusive terminando com as cátedras - e articulou o corpo docente em torno de especialidades dos ramos das ciências. Esse formato tinha como pressuposto o favorecimento das atividades de investigação, e essas passaram a ser valorizadas como estruturantes da carreira docente. Para dar sustentação a esse modelo, houve intensos incentivos à pós-graduação stricto-sensu, formando mestres e doutores, e essa formação se constituiu numa condição para a docência. Como pano de fundo da Reforma, estava a aspiração do governo militar de despolitizar a universidade e de torná-la um braço significativo no processo nacionalista de desenvolvimento econômico.

A abertura democrática mobilizou intensamente a sociedade civil e, por pressuposto, a universidade, que clamava por processos de participação amplos e universais. As teses para a Assembléia Nacional Constituinte de 1988 foram tecidas, em boa parte, nas bases intelectuais da universidade brasileira, que apostava em novos tempos e perspectivas para o país. Dessas teses fazia parte a defesa da indissociabilidade do ensino, da pesquisa e da extensão como base conceitual da universidade, a qual, vencedora, imprimiu esse conceito na Lei Constitucional.

Vale ressaltar, porém, que, embora esse movimento tenha sido muito rico para a sociedade civil, e em especial para a universidade, a maioria da comunidade que dava sustentação aos discursos não fazia uma reflexão conceitual mais aprofundada sobre seu significado. E permaneceu a perspectiva de maior incidência cultural, que centra na Instituição esse processo. Ou seja, se a universidade abriga atividades das três naturezas estaria atendendo ao dispositivo constitucional. Não houve um aprofundamento da expressão "indissociabilidade" na sua condição de impacto epistemológico nos processos de ensinar e aprender. Essa é a posição que compreendemos necessária para assumir o conceito de 
indissociabilidade. Trata-se de compreender esse conceito como uma condição epistemológica de ruptura com a visão do conhecimento posto e instituído, próprio da concepção positivista de ciência. É dar à universidade o estatuto de produtora de conhecimentos, o que, como afirma Readings (2002, p. 24), "equivale a pensar a articulação social da pesquisa e do ensino em termos de missão”. Ao que contribui Santos (2010) quando insiste que a legitimidade da universidade se institui pela proximidade com os problemas sociais e a sua capacidade de responder aos desafios da integração da pesquisa e do ensino com a base concreta da sociedade. Trata-se de uma concepção de indissociabilidade que transcende ao campo epistemológico, mesmo reconhecendo que esse é um fundamental ponto de partida; incorpora a dimensão política, que exige compromisso público e social.

O conceito de indissociabilidade que esses autores defendem pressupóe um deslocar do lugar disciplinar e transcender a uma nova institucionalidade. Entretanto, as mudanças que requeriam uma ruptura com as formas pedagógicas tradicionais faziam-se cada vez mais necessárias. As tecnologias, trazendo novas formas de veiculação da informação; as mudanças no mundo do trabalho, solapando a estabilidade das carreiras tradicionais e exigindo flexibilidade na formação; os discursos relacionados à formação de estudantes críticos e criativos; a democratização do acesso aos bancos acadêmicos, ampliando a interiorização e a massificação da graduação constituíram-se em tensóes e desafios para o campo da educação superior. Mais do que nunca, rupturas epistemológicas e pedagógicas eram requeridas para enfrentar essas demandas.

No âmbito da formação, entretanto, nem sempre esses movimentos vieram concomitantemente. As políticas e as normas regulatórias da formação e da carreira do professor universitário continuam baseadas na concepção que se afasta da relação ensino e pesquisa. Os Programas de Pós-Graduação têm a pesquisa como eixo e se preocupam em formar pesquisadores especializados. Essa condição tem representado um aumento significativo de produção de conhecimento no país, e essa parece ser a meta principal dos órgãos de fomento. Esses Programas, porém, pouco atentam para os saberes do ensino, como se a competência investigativa fosse capaz de transformar os saberes da pesquisa em saberes do ensino. 
A relação ensino e pesquisa certamente está a merecer maiores cuidados e aprofundamento conceitual. É certo que deve haver uma forte articulação entre ensinar/aprender e pesquisar. Como afirma Cury (2009): ${ }^{2}$
[...] só se pode ensinar e aprender significativamente, fecundamente, quando está em pauta a experiência do processo de construção do conhecimento. Não vejo o conhecimento como mera representaçáo mental, mas como o resultado de todo um processamento que atua sobre os dados da experiência.

Para construir essas pontes entre o pesquisar, o ensinar e o aprender, não obstante, requerem-se saberes próprios, que levem em conta o estudante, a cultura e as condiçóes objetivas e contextuais da aprendizagem. O que se observa, porém, é que essa reflexão pouco encontra guarida nos Programas de Pós-Graduação stricto sensu, o que cria hiatos na formação dos docentes da educação superior. Não bastasse essa condição, a carreira do magistério assenta-se na valorização dos produtos da pesquisa, e pouco valor atribui aos saberes da docência.

É paradoxal essa situação. Temos jovens integrantes da carreira universitária, quase no topo de sua progressividade, ${ }^{3}$ considerados professores. Entretanto eles não realizaram estudos do campo da docência e, em geral, não possuem prática profissional na sua área específica. Além disso, possuem uma representação de aluno afastada dos estudantes das classes populares, muitas vezes trabalhadores frequentando cursos noturnos.

Sem desconsiderar a importância da formação investigativa na trajetória destes jovens doutores, denominá-los de professores e pensar que possam estar em condiçóes de compreender propostas curriculares que incluam processos de ensinar e aprender com bases consistentes é uma quimera. Mais ainda, quando se teria a perspectiva de que eles fossem capazes de fazer rupturas epistemológicas e correr riscos de desenvolver uma pedagogia que certamente se afastassem de suas trajetórias estudantis, interpretando a cultura de seus alunos e a importância de articular teoria e prática, a partir de suas vivências.

Também os jovens professores não encontram na universidade uma preocupação mais sistemática com o seu período de inserção profissional. Não há cultura de acolhimento sistematizada entre os pares, e se instala a condição 
naturalizada da docência. São poucas as exceçôes. Não raras vezes, o docente iniciante recebe as disciplinas de menor prestígio em dias e horários que os mais experientes recusam. Seu rito de passagem é construído pela dificuldade e não pelo apoio estruturado, necessário à iniciação profissional. Encontra um ambiente pouco estimulante para as inovaçôes pedagógicas porque também os docentes mais experientes dedicam pouca atenção e tempo à renovação de suas práticas. Inexiste a reflexão coletiva sobre as atividades de ensinar e aprender que realizam. É provável que troquem experiências e conhecimentos sobre as investigaçóes que realizam, mas pouco discutem em que medida sua atividade intelectual interfere na docência que praticam.

A experiência empírica mostra-nos que os percursos de formação dos alunos de graduação, tanto em nível dos currículos, como das práticas pedagógicas, poucas vezes sofreram alteração conceitual, em dependência do perfil pós-graduado dos professores. Também no Reino Unido, Hattie e Marsh, (2000) afirmam não existir uma grande correlação entre os bons professores e os bons investigadores. Se, por um lado, esses se tornaram mais competentes no domínio da pesquisa e do aprofundamento temático de sua área, bem como no desenvolvimento de significativas habilidades intelectuais, não raras vezes essa condição os afasta da necessária visão generalista e da capacidade articuladora de seu campo de conhecimento. Aprofundam a visão formativa pelo olhar da sua especialidade e diminuem a perspectiva de conjunto e a capacidade de apreender o fenômeno na sua totalidade. Convivem com seus pares na lógica departamental, favorecendo o diálogo disciplinar e sendo valorizados pela expertise que demonstram nesse campo. Em geral, pouco sabem sobre o Projeto Pedagógico do Curso de Graduação onde atuam e compreendem com restriçóes o papel de suas disciplinas no cenário curricular e profissional em que está inserido. No caso dos que iniciam a carreira, vivem uma fase que os desafia a serem aceitos pelos pares, suas culturas e rituais. E, como em geral o ensino não ocupa espaço de importância nessa agenda, "aprendem" a ser professores pelo ensaio e erro, inspirados em modelos históricos, sem repartir seus sucessos e frustraçóes a não ser com outros iniciantes. São raras as oportunidades de outras partilhas. Afirma Marcelo García (2009, p. 63) "que essa condição reforça os estudos que apontam a importância das crenças e idéias prévias sobre o ensino na forma como os professores principiantes representam a profissão e vêm a si mesmos como docentes”. 
Como, então, trabalhar com a tensão que envolve ensino e pesquisa no âmbito dos currículos universitários e nas práticas de ensinar e aprender que deveriam ser implementadas? Poderia se afirmar que a formação em pesquisa é dispensável na formação do professor da educação superior? Por outro lado, seria ela suficiente?

Em tese, a pesquisa faz melhores os professores porque os ajuda a pensar, a duvidar, a compreender, e essas são qualidades importantes na docência. Pode-se questionar se o bom ensino decorre da pesquisa, mas é pouco sustentável afirmar que o adjetivo "superior" com o que se qualifica a educação de terceiro grau, não esteja intrinsecamente ligada à condição intelectual de produção do conhecimento, portanto às atividades investigativas. Entretanto, como afirma Hughes (2008, p. 41) "a crença de que existe uma relação entre ensino e pesquisa é mais forte do que as provas reais da mesma”. O autor ressalta, também, que a relação entre ensino e docência nunca se poderá demonstrar de todo e, por essa razão, é que se tem tomado a aprendizagem como foco, elemento central de ambas as dimensões (HUGHES, 2008). Exemplifica que essa perspectiva se constituiu num movimento presente nos anos 1990 no Reino Unido, que aprofundava as relaçóes entre investigação e aprendizagem, alcançando um patamar mais prático em relação aos currículos e às práticas pedagógicas.

Para Elton (2008, p. 146), somente o saber pedagógico pode estabelecer a ponte entre investigação e docência. É ele que torna possível a mediação entre os processos desencadeados em cada uma das dimensóes constituintes da educaçáo superior. Para o autor, trata-se de ensinar um "modo de investigação", considerando os estudantes peças-chave nos planos de estudo. Para fundamentar essa afirmativa, recorre a escritos de Humbolt, em 1810, acerca da futura Universidade de Berlim, defendendo que "as universidades devem propor a docência como se colocassem problemas ainda não resolvidos e, portanto, como um modo de investigação" (ELTON, 2008, p. 148). Elton analisa, entretanto, a realidade da educação superior de forma crítica, dizendo que essa perspectiva passou ao largo das práticas acadêmicas. A tradição das aulas magistrais, centradas na erudição dos professores preponderou no cenário da universidade. Certamente também as condiçóes objetivas do trabalho do professor e de seus estudantes afastam algumas possibilidades. Mas é a cultura e a visão de conhecimento que têm sido o maior entrave para fazer avançar a relação entre ensino e pesquisa. Se 
essa fosse materializada, a função da extensão se daria ao natural, porque a prática seria o ponto de partida do conhecimento a ser ensinado e, portanto, também seu ponto de chegada.

Romper com a perspectiva epistemológica tradicional constitui-se em um processo exigente, que envolve reflexôes e a apropriação teórica dos campos da docência, da aprendizagem e da avaliação (CUNHA, 1988, 2006; MAYOR RUIZ, 2007). Essas, por sua vez, é que podem interferir na compreensão de currículos e práticas pedagógicas inovadoras, que aproximem as dimensóes do ensino e da pesquisa. No contexto preponderante da carreira universitária, há poucos espaços para a construção desses saberes, e um reconhecimento frágil da sua legitimidade. Continua-se, então, com a preponderância dos currículos tradicionais, tomando somente como retórica a propalada indissociabilidade entre ensino e pesquisa.

Os desafios da universidade em tempos de democratização, porém, têm provocado reflexóes sobre os processos pedagógicos a serem implementados. A continuar com as práticas usuais e a manter a representação ideal de aluno a pautar os rituais da aula universitária, gestores, professores e estudantes correm um sério risco de viver imensas frustraçóes de ordem emocional, acadêmica e econômica. É preciso reinventar muitas das práticas acadêmicas para que elas possam dar conta das expectativas que envolvem cumprir seu papel social e de desenvolvimento humano. Essa não é uma tarefa fácil. Exige, como ponto de partida, um compromisso com a democratizaçáo e a crença nas novas geraçóes, mesmo quando as evidências trazem complexidades. Exige também a necessidade de uma competência técnica construída de forma intencional e responsável, onde o reconhecimento dos saberes profissionais da docência seja uma prioridade.

É preciso, como afirma Rowland (2008, p. 134):

[...] que os professores universitários, sendo as pessoas mais capazes de difundir resultados de suas investigações mediante publicações, tenham que ser as mesmas que consigam atrair os alunos para os processos de indagação, já que são outras as habilidades que entram em jogo.

$\mathrm{O}$ autor menciona a necessidade da explicitação do amor intelectual, afirmando que, ao lembrar dos professores que o influenciaram, o que mais 
recorda é a paixão pela matéria, o desejo que demonstravam em contagiálo com esse entusiasmo e com a vontade do descobrimento (ROWLAND, 2008, p. 125). Na visão de Rowland (2008), essa condição tem muito a ver com a forma de entender o papel do descobrimento na aprendizagem:

Se o descobrimento constitui uma parte importante da aprendizagem, igual que na pesquisa, então se poderia atuar com nexo entre a investigação e a docência: o espaço de descobrimento poderia ser um requisito de ambos os campos. Trata-se de um problema de pedagogia, vinculado à relaçáo entre o conhecimento, o que conhece e o que aprende. (ROWLAND, 2008, p. 126).

A necessária reconfiguração do papel docente e discente e das práticas de ensinar e aprender têm feito emergir o campo da pedagogia universitária, debruçando-se sobre as práticas pedagógicas e de reorganização curricular no contexto das mudanças paradigmáticas que assolam a realidade de todo o processo educativo.

Historicamente, o campo da pedagogia não teve identificações com a educação superior. É dela, também, uma parcela de responsabilidade pelo silêncio produzido sobre esse campo, o qual pouco reinvidicou. As emergências decorrentes do questionamento do papel social da educação superior, as mudanças culturais que afetam a distribuição e produção do conhecimento, os dilemas éticos que se colocam como fundamentais são, entre outros, importantes impulsos para uma virada de posição. A universidade, espaço fundamental da crítica social, tem tido dificuldade em olhar criticamente para si. É possível dizer que há certa soberba cultural que dificulta a autocrítica e, como tal, emperra as mudanças nas tradiçóes acadêmicas.

A ampliação das reflexôes sobre currículo e práticas de formação na universidade exige um investimento, aprofundando questóes que necessitam análises mais sistemáticas e corajosas. Esse campo ainda representa uma potencialidade a ser descortinada, tanto na sua dimensão epistemológica e pedagógica como na arena política que envolve tensôes entre culturas e interesses. Na perspectiva epistemológica, é preciso investir na temática conceitual que alia ensino e pesquisa, ampliando a reflexão 
sobre a naturalização com que esse discurso vem sustentando a qualidade da educação superior. Do campo dos conhecimentos pedagógicos é exigida uma base de pesquisa e reflexão, focando o currículo, os processos de ensinar e aprender e sua dimensão de qualidade. Essa perspectiva incide fortemente na concepção de docência e nos saberes necessários ao seu exercício. Também deve ser objeto de preocupação a dimensão política, que poderá ser a mais complexa, pois envolve a revisão de culturas, visóes e interesses corporativos que foram se consolidando por tradição. Entretanto, sendo essas reflexóes emergentes, a universidade faria um bom investimento em aprofundá-las. Seria prudente não se deixar atropelar por novas crises que atinjam mais intensamente sua legitimidade e capacidade de autoavaliar-se e de traçar sua própria trajetória.

Uma agenda propositiva está exigindo uma análise mais intensa da relação ensino e pesquisa, aprofundando o conceito de qualidade da educação superior e de como essas reflexões políticas e posições epistemológicas incidem sobre os currículos e sobre as práticas de ensinar e aprender que se desenvolvem na universidade. Vale tomar como pano de fundo as mudanças sociais e estruturais que produzem fenômenos novos, como a massificação do acesso ao terceiro grau e a emergência desse nível de escolarização para a grande maioria de jovens e adultos. Quantos dilemas nunca foram adequadamente resolvidos? Como as novas configuraçóes estão a exigir revisóes dos conceitos consolidados? Que lugares abrigam a discussão desses temas no cenário acadêmico?

Nóvoa (2005, p. 08) tem provocado a reflexão dos pesquisadores em educação, em interessante construção linguística, tomando a palavra "evidentemente" como objeto. Afirma ele que tudo que se mostra evidente, mente. $\mathrm{O}$ uso dessa figura de linguagem serve para alertar sobre a necessidade de desconfiar das assertivas naturalizadas no campo das ciências sociais. Elas tolhem a possibilidade de uma reflexão mais sistemática e rica sobre o conteúdo que as sustentam.

Talvez o exemplo possa ser uma inspiração para a análise da relação ensino e pesquisa na educação superior. Há, também, nesse caso, um pressuposto inquestionável de que a pesquisa qualifica o ensino e sobre ele há uma tácita concordância que todos ratificamos. Mas será que essa relação se faz de forma tão linear? Sempre que há pesquisa haverá ensino de qualidade? Serão necessárias outras mediaçóes para que essa relação 
aconteça? Quando e em que condiçóes essa assertiva seria confirmada? Que intervenção pedagógica seria importante para esse fim? Os saberes que sustentam a pesquisa serão suficientes para a realização de práticas pedagógicas significativas? Como essas questôes impactam o ensino de graduação na educação superior brasileira? Quando se tornam indicadores de qualidade?

Essas questóes estão mobilizando energias de pesquisa. Como existem distintas percepçóes sobre o discurso da indissociabilidade, o que é importante é a realização de uma análise mais consequente de suas proposiçôes. Mesmo assumindo a diferença e a diversidade como referentes, compreendemos a importância de estabelecer vínculos mais claros entre essas duas dimensóes que nos façam conscientes das perspectivas disciplinares e epistemológicas que estão em pauta. Precisamos compreender como os processos de ensinar e aprender são atingidos pela compreensão da indissociabilidade entre ensino, pesquisa e extensão.

Em tese concordamos com Healey (2008, p. 103) quando afirma que:

[...] em que pese às diferentes formas e incidências, fomentar uma implicaçáo ativa dos estudantes em atividades de pesquisa melhora a qualidade das relaçôes entre ensino e pesquisa e tem influência positiva nas instituiçóes de ensino superior de todos os tipos.

O que não sabemos é se os professores investigadores que atuam na educação superior constroem processos investigativos com seus alunos, e se desenvolvem a docência entendendo a pesquisa e a aprendizagem como comunidades de indagação, onde ambos são agentes de aprendizagem.

$\mathrm{O}$ ensino com pesquisa, que materializaria a concepção de indissociabilidade centrada na aprendizagem, pressupóe um deslocamento da docência centrada no professor para a docência centrada no estudante. E esse movimento processual exige conhecimentos e saberes que os profissionais docentes do ensino superior, em geral, não têm, pois não realizam estudos do campo educacional. Entretanto, quando mobilizam sua condição reflexiva sobre o trabalho que realizam, desenvolvem saberes experienciais importantes e protagonizam, com seus alunos, ações pedagógicas de caráter inovador. Certamente o fariam com mais constância e propriedade se tivessem estudos 
profissionais relacionados à docência em suas trajetórias. Seriam capazes de teorizar o que fazem e compreenderiam melhor os processos que vivenciam junto com os estudantes.

As pesquisas realizadas indicam fatores múltiplos presentes na construção da profissionalidade do docente universitário. Mas são unânimes em apontar a necessidade de investimento em seu desenvolvimento profissional, de forma a construir uma prática pedagógica articuladora da teoria e da prática, bem como da relação ensino e pesquisa. É preciso levar em conta a cultura institucional que favorece a representação de docência e de discência que se quer ver implantadas, e compreendê-las como um ato de permanente aprendizagem.

Esse se constitui num desafio para concretizar os esforços de democratização da educação superior no Brasil, "qualificando a qualidade" da prática pedagógica pela relação ensino e pesquisa. Sem essa condição estaremos fadados a perder oportunidades de desenvolvimento e de dar às novas geraçôes melhores condições de "felicidadania" como adjetiva Rios. Estaremos dispostos a levar a sério essa condição?

\section{Notas}

1 Entrevista concedida à autora como parte empírica da investigação "Qualidade do ensino de graduação: a relação entre ensino, pesquisa e desenvolvimento profissional”.

2 Entrevista concedida à autora como parte empírica da investigação "Qualidade do ensino de graduação: a relação entre ensino, pesquisa e desenvolvimento profissional".

3 No caso da Carreira das IES Federais, o título de doutorado é suficiente para que o recém concursado seja classificado como Professor Adjunto, saltando as etapas de professor Auxiliar e Assistente. 


\section{REFERÊNCIAS}

BARNETT, R. (Ed.). Para uma transformación de la universidad: nuevas relaciones entre investigación, saber y docencia. Barcelona: Octaedro, 2008 .

BRASIL. Lei no 5.540 , de 28 de novembro de 1968. Fixa normas de organização e funcionamento do ensino superior e sua articulaçáo com a escola média, e dá outras providências. Diário Oficial da União, Brasília, p. 10.369, 28 nov. 1968. Disponível em: <https:/www.planalto.gov.br/ ccivil_03/leis/15540.htm>. Acesso em: 5 fev. 2009.

CORTELLA, M. S. A escola e o conhecimento: fundamentos epistemológicos e políticos. São Paulo: Cortez; Instituto Paulo Freire, 1998.

CUNHA, M. I. da. O professor universitário na transição de paradigmas. Araraquara: JM Editores, 1988.

CUNHA, M. I. da (Org.). Pedagogia universitária: inovaçóes pedagógicas em tempos neoliberais. Campinas: JM Editores, 2006.

CURY, C. J. Entrevista concedida. São Leopoldo, RS: Ed. da Unisinos, 2009. Projeto de Pesquisa Qualidade do ensino de graduação: a relação entre ensino, pesquisa e desenvolvimento profissional docente.

DEMO, P. Pesquisa: princípio científico e educativo. São Paulo: Cortez, 1993.

ELTON, L. El saber y el vínculo entre la investigación y la docência. In: BARNETT, R. (Ed.). Para una transformación de la universidad: nuevas relaciones entre investigación, saber y docencia. Barcelona: Octaedro, 2008.

ENRICONE, D. Trajetórias e memórias de constituição do campo da didática. In: ENCONTRO NACIONAL DE DIDÁTICA E PRÁTICA DE ENSINO (ENDIPE), 14., Porto Alegre. Anais... Porto Alegre: ENDIPE, 2008. v. 1, p. 77-88.

HATTIE, M.; MARSH, H. W. The relationship of teaching in higher education: a discipline based approach. Higher Education Research and Development, London, v. 19, n. 2, p. 89-169, 2000. 
HEALEY, M. Vínculos entre docencia e investigación: reflexión en torno a los espacios disciplinares y el papel del aprendizaje basado en la investigación. In: BARNETT, R. (Ed.). Para una transformación de la universidad: nuevas relaciones entre investigación, saber y docencia. Barcelona: Octaedro, 2008.

HUGHES, M. Los mitos en torno de las relaciones entre investigación y docencia en las universidades. In: BARNETT, R. (Ed.). Para una transformación de la universidad: nuevas relaciones entre investigación, saber y docencia. Barcelona: Octaedro, 2008.

MACHADO, N. J. Imagens do conhecimento e ação docente no ensino superior. In: PIMENTA, S.; ALMEIDA, M. I. Pedagogia Universitária. São Paulo: EDUSP, 2009.

MARCELO GARCÍA, C. Formação de professores: para uma mudança educativa. Porto: Porto Editora, 1999.

MARCELO GARCÍA, C. El profesorado principiante: inserción a la docencia. Barcelona: Octaedro, 2009.

MAYOR RUIZ, C. (Org.). El asesoramiento pedagógico para la formación docente del profesorado universitário. Sevilla: Ed. da Universidade de Sevilha, 2007.

MAZZILLI, S. O desafio da indissociabilidade do ensino, da pesquisa e da extensão como movimento de reconfiguração da universidade brasileira na fase de redemocratização do Estado. In: CONGRESSO OF THE LATIN AMERICAN STUDIES ASSOCIATION (LASA), 2007, Montreal. Anais... Montreal, 2007. 1 CD-ROOM. p. 1-19.

NÓVOA, A. Evidentemente: histórias da educação. Lisboa: Asa, 2005.

PAOLI, N.; BALZAN, N. Para repensar a universidade e a pós-graduação. Campinas: Ed. da UNICAMP, 1985.

RAMSDEN, P.; MOSES, I. Associations between research and teaching in Australian higher education. Higher Education, London, n. 23, p. $273-$ 295, 1992.

ROWLAND, S. El amor intelectual y la relación entre la investigación y docencia. In: BARNETT, R. (Ed.). Para una transformación de la 
universidad: nuevas relaciones entre investigación, saber y docencia. Barcelona: Octaedro, 2008.

READINGS, Bill. Universidade sem cultura? 2. ed. Rio de janeiro: Ed. da UERJ, 2002.

SEVERINO, A. J. Ensino e pesquisa na docência universitária: caminhos para a integração. In: PIMENTA, S. G.; ALMEIDA, M. I. de. Pedagogia Universitária. São Paulo: EDUSP, 2009.

SEVERINO, A. J. Entrevista concedida. São Leopoldo, RS: Ed. da Unisinos, 2009b. Projeto de Pesquisa Qualidade do ensino de graduação: a relação entre ensino, pesquisa e desenvolvimento profissional docente.

SANTOS, B. S. A crítica da razáo indolente: contra o desperdício da experiência. São Paulo: Cortez, 2000.

SANTOS, B. S. A universidade no século XXI: pra uma reforma democrática e emancipatória da Universidade. 3. ed. Sáo Paulo: Cortez, 2010 .

STENHOUSE, L. Investigación como base de la enseñanza. 4. ed. Madrid: Morata, 1998.

ZABALZA, Miguel A. La enseñanza universitaria: el escenario y sus protagonistas. Madrid: Narcea, 2002. 


\section{Indissociability between teaching and research: the quality of undergraduate courses in times of democratization}

\section{Abstract}

This paper discusses the premise of the indissociability between teaching and research in the context of university pedagogy. It attempts to understand the forms of production of that discourse, as well as the recontextualizations it needs in order to get inserted into the present times. The paper states that the conceptual fogginess that surrounds the relationship between teaching and research affects the processes of teaching and learning in university, as well as the project of teacher education for those who have their activity at that level of teaching. It recovers the epistemological perspective of teaching with research, stressing the need for rupturing with the conception of modern science which strongly affects the quotidian practices of teaching and learning. Finally, it analyzes the demands that such movement brings to the didactics of higher education, in the direction of pedagogical innovations that treat the relationship between teaching and research as a methodological principle.

Keywords: Quality. Relationship between teaching and research. University Pedagogy.

\section{Indisociabilidad entre educación e investigación: la calidad de la graduación en tiempos de democra- tización}

\section{Resumen}

El texto discute la premisa de la indisociabilidad de la educación y de la investigación en el contexto de la pedagogía universitaria. Busca comprender las formas de producción de ese discurso y las recontextualizaciones necesarias para inserirse en la actualidad. Afirma que la nebulosidad conceptual que envuelve la relación educación e investigación tiene consecuencias en los procesos de enseñar y aprender en la universidad $\mathrm{y}$ en el proyecto de formación de los docentes que actúan en ese nivel de educación. Recupera la perspectiva epistemológica de la educación con investigación trayendo exigencias para la didáctica de la educación superior, en la dirección de innovaciones pedagógicas.

Palavras clave: Calidad. Relación educación e investigación. Pedagogía Universitaria. 


\section{Maria Isabel da Cunha}

Av. Unisinos 950, Bairro Cristo Rei, São Leopoldo, RS. CEP: 930022-000

Telefones: (51) 35908184 / 33928921 / 35908118 (Fax)

E-mail:mabel@unisinos.br

Recebido em: 2/3/2011

Versáo final recebida em: 26/10/2011

Aprovado em: 31/10/2011 